\title{
SOBRE O SIGNIFICADO DE UMA GENEALOGIA DE Si No Livro AUrora de NiETzSCHE ('SI' COMO O PRÓPRIO NIETZSCHE E COMO FILÓSOFO) ${ }^{1}$
}

\author{
Jorge Luiz Viesenteiner \\ Universidade Federal do Espírito Santo - Brasil
}

\section{A estratégia crítica de uma genealogia de si: práxis interrogativa e distanciamento}

O texto de Aurora - ao lado de $A$ gaia ciência - é marcado pela assim denominada crise de "in media vita" (GC 324)2. Uma espécie de período de autodecisão, bem como um tempo que Nietzsche alcança um grau elevadíssimo com sua própria doença física, visto por ele como paradoxal

\footnotetext{
1 Esse texto foi originalmente apresentado no V Congresso Internacional do GIRN (Groupe International de Recherches sur Nietzsche), intitulado "Aurora: uma viragem na obra de Nietzsche?", e que ocorreu em Lisboa/ Portugal, entre os dias 21 e 23 de julho de 2012. $\mathrm{O}$ artigo é uma versão ampliada e melhorada da conferência. Meus agradecimentos a todos os membros do GIRN pelo debate e sugestões que, certamente, enriqueceram e muito esse artigo.

2 Emprego as seguintes abreviações usuais para as obras de Nietzsche. Nos apontamentos póstumos, indico o ano do apontamento, seu número, seguido da referência na KSA (Kritische Studienausgabe - a edição crítica das obras completas de Nietzsche) com o número do volume e página (p.ex.: Nachlass 1888, 9[1], KSA 8, p. 23). Para as referências de obras enviadas a publicação de Nietzsche, segue-se a abreviação do livro (p.ex., HH para Humano, demasiado humano; A para Aurora; GC para A Gaia Ciência; ABM para Além do bem e do mal; CW para O caso Wagner; EH para Ecce homo) e número do aforismo (p.ex., A 33; GC 343, EH, Aurora 1, etc.). As traduções dos apontamentos póstumos e da bibliografia em alemão são de minha autoria. Privilegio as traduções de Paulo César de Souza ao citar as obras publicadas em português, editadas pela Companhia das Letras.
}

Philosophica, 45, Lisboa, 2015, pp. 39-55. 
instante "a um tempo décadent e começo": "aos trinta e seis anos atingi o ponto mais baixo de minha vitalidade - ainda vivia, sem no entanto enxergar três passos adiante. Então - era o ano de 1879 - abandonei minha cátedra na Basiléia [...]" (EH, Por que sou tão sábio 1$).{ }^{3}$ Um novo horizonte vai se impor diante de Nietzsche, sobretudo a partir do inverno de 1879-1880. Mas os anos de sofrimento de in media vita deverão abrir também um novo prelúdio e uma nova "aurora": "um instante de suprema tomada de consciência, um grande meio dia". (EH, Aurora 2$)^{4}$

Aurora é um dos primeiros textos publicados no qual Nietzsche, de forma um pouco mais sistemática - apesar dos aforismos -, realiza sua assim denominada "campanha contra a moral" (EH, Aurora 1), ao empregar uma estratégia de distanciamento que é, simultaneamente, um dos mais adequados instrumentos críticos para uma genealogia de si. "Solapar nossa confiança na moral" consiste no "último adeus" (A, Prólogo 2) dado por um "ser subterrâneo" (A, Prólogo 1), e que prepara a humanidade, e inclusive o próprio Nietzsche, para colocar a "questão do por quê?, do para quê? pela primeira vez como um todo" (EH, Aurora 2). Essa práxis interrogativa contra a moral, porém, também é dirigida, ao mesmo tempo, contra si mesmo, na medida em que foi justamente ela que o guiou na

3 Para uma minuciosa análise de Aurora, cf. Marco Brusotti, Die Leidenschaft der Erkenntnis: Philosophie und ästhetische Lebensgestaltung bei Nietzsche von Morgenröthe bis Also Sprach Zarathustra. (Monographien und Texte zur NietzscheForschung). Berlin/New York: Walter de Gruyter, 1997, p. 179: “O meio da vida é [...] um estado de oscilação entre duas épocas da vida. [...] ele é um tempo de decisão. Mas Nietzsche vivencia o fim do ano de 1879 - em 15 de outubro ele completou seus 35 anos - como o ponto mais alto da própria doença”. Cf. Também Friedrich Kaulbach, Nietzsches Idee einer Experimentalphilosophie. Köln/Wien: Böhlau, 1980, p. 97s.

4 É importante chamar atenção para a mudança que ocorreu no título do livro, pois a partir dela é que justifico Aurora como o livro no qual Nietzsche, de modo bem-sucedido, realiza uma das primeiras tentativas de genealogia de si mesmo. Em 25 de janeiro de 1881, quando Nietzsche envia a Peter Gast seu novo escrito, ele foi originalmente intitulado como "Die Pflugschar. Gedanken über die moralischen Vorurtheile" (A relha. Pensamentos sobre os preconceitos morais). Com a referência escrita por Peter Gast dos Rigveda - "há tantas auroras que ainda não brilharam" - Nietzsche se entusiasma e altera o título 'Pflugschar' (relha) para "Morgenröthe. Gedanken über die moralischen Vorurtheile" (Aurora. Pensamentos sobre os preconceitos morais). (cf. KSA 14, p. 203) Seja 'Pflugschar' (relha), ou 'Morgenröthe' (aurora), ambos sempre apontam para um futuro, indicam novas possibilidades e outros horizontes, ou, em suma, o anseio por um "caminho próprio", conforme Nietzsche intitulará tanto no aforismo 484, quanto no aforismo 2 do 'Prólogo' tardio de 1886 de Aurora. Assim, o uso agrícola da relha para o plantio das sementes alude ao que ainda está porvir e vai nascer, ao passo que Aurora igualmente indica uma nova esperança. Ambos os títulos aludem a um recomeço, uma nova fase, uma outra perspectiva. Por isso que situo em Aurora, especificamente, uma das primeiras tentativas bem-sucedidas de Nietzsche de uma autogenealogia. 
estratégia de distanciamento da assim denominada "ilusão da ordem moral do mundo" (A 563), que como veremos a seguir, é o horizonte teórico que precisa ser considerado como lente de aumento para o próprio Nietzsche. No Ecce homo, sua autogenealogia filosófica, ao referir-se à Aurora como um "livro que diz Sim", de modo que nele "não se encontre uma só palavra negativa, um ataque, uma malícia", refere-se também à metáfora do "animal marinho" que toma sol por conta de tais interrogações, acrescentando que ele próprio foi esse animal (EH, Aurora 1), da mesma maneira que o "ser subterrâneo" do 'Prólogo' tardio também é o próprio Nietzsche, isto é, o filósofo Nietzsche que dá seu 'último adeus' à moral.

As perguntas pelo 'por quê?' e 'para quê?' são aquelas com as quais Nietzsche opera o distanciamento da ilusão da ordem moral do mundo, uma "tarefa" que ele assume para si mesmo "pela primeira vez", e que consiste precisamente em preparar a humanidade para o ato de "suprema tomada de consciência" (EH, Aurora 2). Não se trata de um "ataque" que objetiva destruir a moral, mas a moral mesma "apenas não é mais considerada...", ou seja, uma habilidade crítica de "desprender-se de todos os valores morais" (EH, Aurora 1), ou ainda da Circe moral que governou os homens tão "sedutoramente". Dessa forma, a práxis interrogativa direcionada tanto contra a moral, quanto contra si mesmo, não constitui nenhuma negação da moral, mas apenas uma estratégia crítica de distanciamento, um 'último adeus' à 'confiança na moral' (A, Prólogo 2) e, por isso, o texto de Aurora não tem "o menor cheiro de pólvora" e também não é nenhuma "artilharia" (EH, Aurora 1).

Ao identificar-se com o animal marinho e o ser subterrâneo, o próprio Nietzsche é que pretende se distanciar e desprender dos valores morais, empregando para isso a mesma práxis interrogativa do 'por quê?' e 'para quê?', direcionada agora contra ele mesmo, cuja estratégia caracteriza sua tentativa de autogenealogia. Por meio das perguntas do 'por quê?' e 'para quê?' Nietzsche pode ser, a um só tempo, 'décadent e começo': por um lado, trata-se da honestidade intelectual que reconhece a si mesmo seduzido pela Circe moral - ao encenar a si mesmo como 'décadent' -, incluindo-se no mesmo processo decadencial que é criticado por ele; por outro lado, e 'a um só tempo', inicia a 'campanha contra a moral' - ao encenar-se como 'começo' - distanciando-se, portanto, desse mesmo processo decadencial. 'Décadent e começo' carregam tanto o reconhecimento honesto de que também foi seduzido pela moral, quanto a estratégia de distanciamento: ambos procedimentos da mesma tentativa crítica de entender melhor, genealogicamente, a si mesmo, e a si mesmo como filósofo. ${ }^{5}$

Essa estratégia na qual Nietzsche se distancia dos valores morais, a partir dos próprios valores morais, tão logo insere a si próprio no mesmo processo que critica, pode ser compreendida por meio do conceito de extemporaneidade (Unzeitgemäßheit). Compreendo 'extemporaneidade' como um distanciamento da situação, na situação. 
Enfatizo aqui o aspecto autogenealógico da práxis interrogativa de Aurora. Ao se reconhecer 'décadent' e questionar a sedução moral, Nietzsche igualmente opera um criticismo de si mesmo, na qualidade de alguém também seduzido por Circes. Isso significa efetiva práxis crítica que não reivindica nenhum espaço supostamente imune de onde se poderia criticar algo. Se a 'confiança na moral' é um dos objetos de análise em Aurora, Nietzsche não pode se colocar num pretenso lugar extrínseco à própria moralidade, indicando o que poderia significar uma moralidade destituída de seduções. Ao encenar-se 'décadent', porém, encena-se como mais um seduzido por Circes, de modo que sua práxis interrogativa significa, no fundo, exercício autocrítico e, por isso, tentativa de compreensão genealógica de si mesmo. Não há nada aí de autoconhecimento, mas sim autogenealogia.

Outro aspecto importante do sentido autogenealógico de Aurora é a vinculação que faço com a noção de distanciamento, entendido aqui como diferenciação da diferenciação ${ }^{6}$. Encenando-se como alguém inserido nas seduções, por exemplo, a Circe da 'ilusão da ordem moral', Nietzsche enxerga, põe em evidência e diferencia cada preconceito moral, enquanto

Situo-me aqui no 'Prólogo' da segunda Consideração Extemporânea, intitulada $D a$ utilidade e desvantagem da história para a vida, especialmente onde se lê: "pois não saberia o que a filologia clássica na nossa época tomaria por sentido, a não ser atuar extemporaneamente - ou seja, contra a época e, com isso, na época e, talvez, em favor de uma época por vir.” (Cons. Ext. II, HL, Prólogo. In: KSA 1, p. 247. O grifo é meu). Tão logo Nietzsche reconhece a si próprio seduzido pela Circe moral - 'décadent'-, ele também tem de criticar, indiretamente, a si mesmo, para então se distanciar do mesmo processo de sedução moral - 'começo'. Como filósofo extemporâneo, portanto, Nietzsche se distancia da sedução moral, na própria sedução moral. Com o conceito de extemporaneidade, além disso, fica mais claro o porquê Aurora não opera um 'ataque', mas apenas um distanciamento crítico: Nietzsche não precisa destruir a moral, mas apenas distanciar-se da moral na própria moralidade.

6 Tal definição pode perfeitamente se desdobrar naquilo que em Para além de bem e mal será caracterizado como "pathos da distância": o "desejo de sempre aumentar a distância no interior da própria alma, a elaboração de estados sempre mais elevados, mais raros, remotos, amplos, abrangentes", bem como a habilidade de enxergar "hierarquias e diferenças de valor entre um e outro homem" (ABM 257). Em sua autogenealogia Ecce homo, Nietzsche também escreve a propósito da habilidade da distância e de diferenciar: "A primeira coisa em que peso o coração de um homem é se ele tem dentro de si um sentimento de distância, se enxerga em toda parte posição, ordem, grau entre um homem e outro, se distingue: com isso é um gentilhomme;" (EH, O caso Wagner 4) Justamente tal habilidade de distância e diferenciação é que, no mesmo aforismo, faz com que Nietzsche se autodenomine uma "nuance". Sobre o tema, cf. Werner Stegmaier, "Nietzsches Kritik der Vernunft seines Lebens: Zur Deutung von Der Antichrist und Ecce homo", Nietzsche-Studien 21 (1992b) p. 163-183 e Patrick Wotling, Nietzsche et le problème de la civilasation. Paris: PUF, 1995 (especialmente o capítulo em que o autor analisa a fórmula "eu sou uma nuance"). 
preconceito, para então tomar distância desses preconceitos e novamente diferenciar a si próprio em relação ao que ele diferenciou. Trata-se de uma dupla diferenciação: diferenciar preconceitos, para então se autodiferenciar relativamente às diferenciações. Para essa finalidade, tal como veremos adiante, a análise crítica da 'ilusão da ordem moral do mundo' exerce o papel de lente de aumento para Nietzsche, um dos preconceitos contra o qual ele tem de se distanciar para diferenciar a si mesmo. Portanto, tanto a práxis interrogativa, como o distanciamento entendido como diferenciação da diferenciação exprimem a estratégia crítica com a qual Nietzsche opera em Aurora uma autogenealogia.

Para intensificar ainda mais o horizonte autogenealógico de Aurora, chamo atenção para o fato de que o livro termina, curiosamente, com mais uma pergunta, termina com um 'ou?': o "livro conclui com um 'ou?" escreve Nietzsche em Ecce homo, e novamente pergunta: "é o único livro que conclui com um 'ou?'..." (EH, Aurora 1). A genealogia de si é levada às últimas consequências, no instante em que Nietzsche finaliza o próprio livro com mais uma pergunta. No último aforismo, após escrever sobre seu fatal destino de "naufragar no infinito", pergunta: "Ou então, meus irmãos? Ou?" (Oder, meine Brüder? Oder?) (A 575)

Coloco em evidência dois aspectos dessa intensificação autogenealógica. 1) Concluir o livro com uma pergunta final é conferir a ela a função de mola propulsora para que uma filosofia tire suas últimas consequências e, ao final, volte-se precisamente contra aquele pergunta, a saber, o próprio Nietzsche. O questionamento que o distancia da ordem moral termina, no final das contas, por questionar a totalidade do seu próprio questionamento, de modo que a pergunta final 'ou?' tem de se voltar agora contra o próprio livro e, simultaneamente, contra si mesmo como autoquestionamento. Trata-se tanto da práxis crítica que questiona os preconceitos, distanciando-se da ordem moral, como também a pergunta final contra o próprio procedimento crítico: a pergunta final 'ou?' força a filosofia de Nietzsche se autorrefletir sobre seu próprio autor. ${ }^{7}$

2) A pergunta final 'ou?' (oder), além disso, é uma pergunta que envolve direta e imediatamente os interlocutores na conversação: "Oder, meine Brüder? Oder”, assim pergunta Nietzsche. Em alemão, a pergunta final 'oder?' exerce uma forte função de performatividade, diretamente direcionada ao interlocutor, forçando-o a tomar partido também sobre o que é dito, independente do posicionamento positivo ou negativo que

Cf. Paul van Tongeren, “O filósofo como clínico da crítica à cultura”, Estudos Nietzsche (Trad. Jorge L. Viesenteiner) v.1/n.2 (2010), pp. 265ss. 
venha a ter. A pergunta final de Aurora, 'oder?', não apenas exprime a autorreflexividade do questionamento de Nietzsche, intratextualmente, mas é também a coerção que impele o leitor à individualização do pensamento, que o força a refletir sobre o quanto também está seduzido pelos preconceitos morais, obrigando-o a realizar a mesma tentativa crítica de compreender a si mesmo genealogicamente. Trata-se aqui de uma estratégia literária que é marcada pelo signo da performatividade. Dessa maneira, talvez, possamos entender melhor porque não se trata apenas de uma genealogia de si, mas também um dos primeiros momentos em que Nietzsche, por meio de Aurora, envolve seus próprios leitores, forçando-os a uma individualização do pensamento: "Oder, meine Brüder? Oder?", e agora direciono a própria hipótese desse artigo contra mim mesmo, ao empregar a pergunta final de Nietzsche aos leitores do meu texto, inserindo a mim mesmo, como leitor de Nietzsche e por honestidade intelectual, no mesmo jogo de interrogação e distanciamento.

Em termos específicos, a práxis autogenealógica é conduzida pela estratégia de distanciamento dos 'erros da razão', na medida em que a confrontação crítica e o esvaziamento das 'coisas imaginadas' exercem o papel de lente de aumento para Nietzsche compreender melhor a si mesmo. Uma maneira possível de interpretarmos essa hipótese é através do confronto crítico de Nietzsche com a assim denominada "ilusão da ordem moral do mundo" (A 563), que é sustentada pela frase emprestada de Entretiens de Epicteto ${ }^{8}$, e repetida por Nietzsche no mesmo aforismo 563: "Não as coisas, mas as opiniões sobre coisas que não existem, perturbaram dessa forma a humanidade!" Trata-se da "purificação dos sentimentos superiores” (A 33), do distanciamento dos 'erros da razão' que fazem o doente ser culpado, pois assim ele 'se sente' (A 148), algo que, no fundo, é mera confusão entre "conceitos morais e sentimentos morais" (A 34). Nietzsche tem de diferenciar cada preconceito da assim denominada 'ilusão da ordem moral do mundo', para então posicionar-se em relação às suas diferenciações. A seguir, procedemos à análise técnica do aforismo intitulado "A ilusão da ordem moral do mundo".

8 Cf. Epicteto, Entretiens. Trad. Joseph Souilhé. 1943-1965. 4v. (Col. Belles Lettres), 2007, p. 25: "o que perturba os homens não são as coisas, mas os seus julgamentos sobre estas coisas." Sobre o tema, cf. também Antônio C. Tarquínio, "Epicteto e a paixão no coração do pensamento. As duas causas de Crisipo e o mergulho em Deus", Cadernos UFS-Filosofia 5 (2009) p. 40. A expressão também é citada por Arthur Schopenhauer, Aforismos para sabedoria de vida. Trad. Jair Barboza. São Paulo: Martins Fontes, 2006, p. 19. 


\section{Aforismo 563: a confrontação com a 'ilusão da ordem moral do mundo'}

Uma hipótese possível para analisar uma tentativa de genealogia de si em Aurora é investigar a confrontação de Nietzsche com a "ordenação moral do mundo". O projeto crítico de Aurora ataca diretamente tanto os sentimentos quanto os juízos morais (A 453). ${ }^{10}$ No fundo, é um texto em que Nietzsche faz uma profunda retrospectiva sobre suas condições de

Peter D. Murray, Nietzsche's Affirmative Morality: a revaluation based in the Dionysian World-View. Berlin/New York: Walter de Gruyter, 1999, pp. 149-154.

10 Embora não seja meu objeto de estudo a análise da gênese da consciência moral, é importante registrar, no rigoroso âmbito de Aurora, as diferenças entre juízo e sentimento moral. O conceito de "moralidade do costume" (A 9), que Nietzsche toma como conceito presente na hipótese do período da pré-história da humanidade, grosso modo, é a obediência à "maneira tradicional de agir e avaliar" um costume, sendo imoral precisamente aquele que destoa dessas avaliações agindo, p.ex., em utilidade própria, uma vez que "ela exigia que alguém observasse os preceitos sem pensar em si como indivíduo" (idem). O processo de moralização produz um imenso orgulho, ou sentimento de orgulho, e que, por isso, torna-a "a verdadeira e decisiva história que determinou o caráter da humanidade: em que o sofrimento era virtude, a crueldade..., a dissimulação..., a vingança..., a negação da razão..., enquanto o bem-estar era perigo..., a paz era perigo, a compaixão..." (A 18). À época da moralidade dos costumes há um forte sentimento de poder alcançado pela comunidade, de tal modo que os costumes são a tradução imediata desse sentimento de poder e orgulho. Neste sentido, Nietzsche diferencia o costume mesmo e o sentimento do costume: "o costume representa as experiências dos homens passados acerca do que presumiam ser útil ou prejudicial - mas o sentimento do costume (moralidade) não diz respeito àquelas experiências como tais, e sim à idade, santidade, indiscutibilidade do costume" (A 19). O recurso hipotético de Nietzsche sobre a préhistória da humanidade, em que imperava a moralidade dos costumes, diferencia-se de um outro período que ele chama de "história universal" (A 18). Nela, os acasos ruins como "súbita tempestade, seca ou epidemia - levam todos os seus membros a suspeitar que foram cometidas infrações ao costume [...] ou apaziguar um humor demoníaco" (A 33). Ocorre, pois, uma inversão de interpretação, de modo que a causa demoníaca é tomada "por pressuposto", e as consequências sobrenaturais, "as chamadas punições e graças da divindade", ganham corpo e se estabelecem na comunidade. Doravante, punições e castigos são avaliados segundo a obediência ou não aos costumes, bem como as consequências sobrenaturais da desobediência. Esse desenvolvimento termina por criar "um mundo imaginário: o chamado mundo superior" (A 33. Nos textos de Nietzsche, essa questão é ampliada principalmente na Genealogia e n'O Anticristo). Com base nisso, o sentimento se distancia do juízo moral. Na medida em que os sentimentos morais são transmitidos e "imitados", logo em seguida e por "questão de decência", questiona-se um "Por quê? posterior" para "uma espécie de fundamentação para as inclinações e aversões: Mas essas 'fundamentações' nada têm a ver com a origem ou o grau do sentimento: o indivíduo apenas acomoda-se à regra [...]. Neste sentido, a história dos sentimentos morais é muito diferente da história dos conceitos morais. Aqueles são poderosos antes da ação, estes depois da ação, em vista da necessidade de pronunciar-se sobre ela" (A 34). Nietzsche acrescenta ainda que, no fundo, os sentimentos são geralmente provenientes de um juízo que é "frequentemente errado!" (A 35). 
vida e reconhece aí "precisamente um estado passional", conforme escreve em carta a Heinrich Köselitz de 23 de junho de 1881 (KSB 6, carta n. 119). No fundo, essa passionalidade precisa ser a condutora do projeto de congelamento das ilusões morais. $\mathrm{O}$ gradual processo com o qual o homem se torna estranho a si próprio produz o que Nietzsche chama de "segunda natureza", que é carregada de um cortejo de preconceitos morais, impedindo o desenvolvimento e a maturação da "primeira natureza", só descoberta quando se ousa trocar a pele: "Tal como agora nos educam, adquirimos primeiro uma segunda natureza: e a temos quando o mundo nos considera maduros, maiores de idade, utilizáveis. Alguns poucos são cobras o bastante para um dia desfazer-se dessa pele: quando, sob seu invólucro, sua primeira natureza tornou-se madura. Na maioria, o gérmen dela ressecou." (A 455)

A segunda natureza é produzida, por um lado, pelos "sentimentos morais" legados, oriundos de uma falsa interpretação do mundo e da vida (cf. A 33), p.ex., quando a comunidade interpreta sua "infelicidade" e "acredita ter feito uma violação" (Nachlass verão 1880, 4[13], KSA 9, p. 104) em relação aos deuses, de modo que resta a ela apenas a expiação desse "mundo imaginário" (A 33). Por outro lado, na medida em que o sentimento dos costumes se converte em opiniões e costumes, com o passar do tempo o "indivíduo" acaba por simplesmente se "acomodar à regra", perdendo contato com a atmosfera do sentimento moral original. O resultado desse processo é que "a história dos sentimentos morais é muito diferente da história dos conceitos morais" (A 34). ${ }^{11}$ A crítica aos preconceitos e ilusões morais, portanto, pressupõe precisamente o congelamento da segunda natureza, a fim de iniciar a lenta escalada nietzscheana de distanciamento da ordem moral do mundo.

A questão de fundo é "mudar de pele" (A 573) e, sobretudo, livrar-se das opiniões adquiridas, bem como das valorações adotadas: "nós aprendemos antes as sentenças e opiniões dos outros do que as nossas próprias; cada uma delas é organizada por meio de um longo exercício sobre nós." (Nachlass primavera 1880, 3[24], KSA 9, p. 53) O preconceito da ilusão da ordem moral do mundo é desmascarado precisamente nessa mesma direção. Na medida em que os juízos morais atravessam e recortam os homens, resulta que não são as coisas mesmas que causam sofrimento, mas as opiniões sobre as coisas que intensificam no homem a consideração de sua eterna existência culpada. Por isso não passa de loucura e insensatez

1 Cf. Marco Brusotti, Die Leidenschaft der Erkenntnis, p. 231: “O espiritual médico dos pobres e esses novos médicos da alma têm tarefas em comum. Ambos se referem, respectivamente, aos juízos (espírito) e sentimentos (alma), os dois conceitos fundamentais na crítica à moral de Aurora." 
"fazer sentir a existência mesma como punição" (A 13). O aforismo que inaugura essa reflexão é o seguinte:

A ilusão da ordem moral do mundo - Não há nenhuma necessidade eterna que exija que toda culpa seja paga e expiada - foi uma ilusão terrível, útil num grau mínimo, crer que tal coisa existisse -; assim como é uma ilusão que seja culpa tudo o que é sentido como tal. Não as coisas, mas as opiniões sobre as coisas que não existem, perturbaram dessa forma a humanidade! (A 563) $)^{12}$

Oriundo do "sentimento da impotência e do medo" (A 23), a falsa interpretação do mundo em termos de categorias imaginárias como culpa, castigo, pecado e afins - todos meios fanáticos de ilusório sentimento de poder -, tem por objetivo algo muito maior: o sentimento ou "impulso para a distinção" (A 30), sentir-se diferente e mais elevado porque através dessa interpretação equivocada, o doente agrega a si, ou assim pretende, dar um valor muito maior do que possui: a "presunção". ${ }^{13}$

Nietzsche também se referiu a esse "impulso para a distinção" como "refinada crueldade", característica com a qual o impotente imputa a si mesmo o direito de condenar os outros, porque supõe ter o privilégio de acessar o mundo superior das coisas imaginadas. Seu desejo oculto é que a "simples vista cause dor ao outro e desperte sua inveja." (A 30) Na base dessa equação se encontram os chamados "sentimentos superiores" que, se para os doentes servem de consolo, para o homem científico e passional -o homem do conhecimento - são ilusões que devem ser purificadas: "É triste, mas por enquanto todos os sentimentos superiores têm de ser suspeitos para o homem científico, de tal modo se acham mesclados com a ilusão e o

12 Cf. ainda, A 13, 33, 100, 148, 202, 425 e 449 e os apontamentos póstumos do verão de 1880, 4[13. 143] e 5[41], KSA 9.

13 Definida por Nietzsche como "um orgulho representado e fingido" (A 291) em que o presunçoso objetiva querer "significar mais do que é ou aquilo por que é tido" (HH 373), a presunção é uma ferramenta indispensável para o fanático e impotente alcançar o ilusório sentimento de poder. O termo ocorre com muita frequência no capítulo de Humano... "O homem a sós consigo" e, principalmente, no livro IV de Aurora onde Nietzsche faz uma verdadeira sondagem experimental da alma humana, revelando sua refinada e sutil habilidade de psicólogo. Ao lado do falso orgulho e da vaidade, a presunção exerce a função de genuíno meio de consolo. Vejamos um ilustrativo aforismo de Humano..., 590, intitulado "A presunção como o último meio de consolo": "Quando alguém interpreta um infortúnio, sua carência intelectual, sua doença, de modo a ver nele um destino predeterminado, uma provação ou a misteriosa punição por algo cometido no passado, torna o próprio ser interessante para si mesmo e se eleva, na imaginação, acima dos semelhantes. O pecador orgulhoso é uma figura conhecida em todas as seitas das igrejas". Não por acaso a presunção é, para Nietzsche, um dos sentimentos que mais devemos prevenir para que não seja pisoteado pelos outros com os "pés sujos" (HH 373). 
contra-senso. Não que tenham de sê-lo em si ou para sempre: mas é certo que, de todas as graduais purificações que esperam a humanidade, a purificação dos sentimentos superiores será uma das mais graduais." (A 33)

Uma interessante figura de pensamento para o tema é o modo com o qual os assim denominados "médicos da alma" precisam operar, a fim de oferecer uma significação moral: eles convencem a todos que o mundo é um fardo a suportar e a vida uma somatória de lamentos e enganos. A necessidade de se convencer acerca da infelicidade pessoal é apenas o início dos procedimentos dos "médicos da alma", e o passo seguinte é oferecer aos seus doentes um alívio. ${ }^{14}$ Neste sentido, na medida em que os médicos receitam seus bálsamos, a consequência é fazer os doentes sofrerem precisamente com as opiniões acerca da doença e, portanto, com as falsas interpretações do caráter global da vida, tal como rezava a hipótese da ilusão da ordem moral do mundo, vale dizer, "não as coisas, mas as opiniões sobre as coisas que não existem [a culpa, p.ex. - JLV], perturbaram dessa forma a humanidade."

No gradual processo em que se subtrai às coisas a "fantasmagoria e todo o humano acréscimo" (GC 57), os juízos e os sentimentos morais também são diminuídos. Trata-se da sutil tarefa de psicólogos - a marca do livro II de Aurora - que, ao invés de supostamente curar o doente como fazem os "médicos da alma", assumem a função de desmascarar os falsos problemas ou conflitos, ilusões e preconceitos. Antes de se asfixiar com a culpa torturante, importa esvaziar as fantasmagorias que preenchem esse excesso de sentimento, ou ainda, reconhecer que "não mais se considerando mau, o homem deixa de sê-lo!" (A 148) No horizonte autogenealógico, a tarefa dos psicólogos é a mesma tarefa que Nietzsche também reivindica para si: como 'décadent', ele é quem mais precisa se distanciar das 'opiniões sobre as coisas que não existem', de modo que a instrumentalização crítica de tal preconceito é, como vimos, autocrítica.

A hipótese de psicólogo ${ }^{15}$ é exatamente a mesma que compunha a

14 Note-se que já nos textos da segunda fase de Nietzsche é possível encontrar o germe do procedimento ascético que vai aparecer depois em Genealogia da moral. Além disso, ocorre também nesse instante uma das críticas que Nietzsche fará em 1888 a Wagner, qual seja, a acusação de que o "artista da décadence" (CW 5) seria um "ator" por transformar a música em uma somatória de estímulos que anestesiam os cansados do mundo e da vida (CW 9) e, portanto, música cuja finalidade é meramente produzir efeito e entretenimento (CW 6). Veja-se, p.ex., A 539: "como vocês frequentemente buscam o que produz efeito forte e o que tranquiliza - porque estão cansados!"

15 A propósito de empregar o termo psicologia, considero essencial registrar que a hipótese do sofrimento com falsos problemas, preconceitos e ilusões morais ou "sentimentos superiores", não está em oposição ao modo como Nietzsche analisará a psicologia em Além do bem e do mal, 23. Ali, após tê-la definido como "morfologia e teoria da 
segunda parte do aforismo analisado anteriormente, vale dizer, "Não as coisas, mas as opiniões sobre as coisas que não existem, perturbaram dessa forma a humanidade." (A 563) Se à base da tentativa de uma genealogia de si se encontra a supressão da ordem moral do mundo, então, para essa tarefa é preciso outro tipo de médico. Não mais aquele que prescreve narcóticos e superestima sentimentos imaginários, mas sobretudo "médicos para os quais isso que chamamos de moral prática deverá ter se transformado num aspecto de sua arte e ciência da cura": "Como seria aliviado o sentimento geral da vida, se juntamente com a crença na culpa nos livrássemos do velho instinto de vingança e olhássemos como sutil inteligência dos felizes o fato de bendizer seus inimigos, como o cristianismo, e fazer $o$ bem aos que nos ofenderam! Vamos retirar do mundo o conceito de pecado - e enviar logo atrás dele o conceito de castigo!" (A 202) Como se vê, a práxis interrogativa do psicólogo Nietzsche é aquela que o faz se distanciar da máxima "todo doente é culpado!", para deslocá-la por meio de outra pergunta: "Não deveríamos poder dizer: todo 'culpado' é um doente?" (A 202) - aliás, direcionando as perguntas aos seus leitores sempre cuidadosamente, visto que nessa pergunta ele emprega até mesmo o verbo 'dürfen'.

Em sua autogenealogia Ecce homo, Nietzsche anuncia a "tarefa" de preparar o instante de "tomada de consciência", por meio da práxis interrogativa - 'por quê?' e 'para quê?'. No 'Prólogo' tardio de 1886, curiosamente, a 'tarefa' para uma nova 'aurora' - justamente aquela de "solapar nossa confiança na moral" - é seguida novamente por uma pergunta direcionada diretamente aos seus leitores: "Estão me compreendendo?” (A, Prólogo 1) É preciso registrar que, originariamente, essa 'tarefa' também é apresentada no interior de Aurora e inclusive à La Epicteto, precisamente no aforismo intitulado "Os pensamentos acerca da doença", cujo anúncio é finalizado novamente com uma pergunta: "Compreendem agora a nossa tarefa?": "Tranquilizar a imaginação do doente, para que ao menos, como até agora, ele não sofra mais com seus pensamentos acerca da doença

evolução da vontade de poder", Nietzsche se refere precisamente aos preconceitos morais que remontam também à carga ilusória atribuída às coisas, como aquilo que o investigador tem de "lutar com resistências": "A força dos preconceitos morais penetrou profundamente no mundo mais espiritual, aparentemente mais frio e mais livre de pressupostos - de maneira inevitavelmente nociva, inibidora, ofuscante, deturpadora. Uma autêntica fisio-psicologia tem de lutar com resistências inconscientes no coração do investigador...". Esvaziar as ilusões e preconceitos que povoam a somatória de sentimentos e juízos morais, ou ainda, restituir às coisas o que é seu, parece estar em total sintonia com a fórmula suprema que caracteriza a tarefa da psicologia de versar sobre o "caminho para os problemas fundamentais". 
do que com a própria doença - creio que isso é algo! Não é pouco! Compreendem agora nossa tarefa?" (A 54) Nietzsche confronta seus leitores e, indiretamente, a si mesmo com a estratégia de ininterrupto questionamento.

A conexão que estabeleço entre o aforismo 54 e o 563 é precisamente a 'tarefa' comum a ambos, a saber, o distanciamento crítico das 'opiniões sobre as coisas que não existem': o preconceito das coisas imaginadas. Trata-se, portanto, da tarefa do psicólogo Nietzsche guiada pela práxis interrogativa contra si mesmo e contra seu leitor: "Não deveríamos [dürfen] poder dizer: todo 'culpado' é um doente?" A análise do aforismo sobre 'a ilusão da ordem moral do mundo' tem de servir, nesse caso, como lente de aumento empregada por Nietzsche para compreenda melhor, no fundo, a si mesmo.

\section{Nietzsche e 'Don Juan do conhecimento'}

Nessas últimas considerações, gostaria de relacionar minha hipótese autogenealógica em Aurora, contextualmente, com a figura de pensamento empregada por Nietzsche nesse livro, o 'Don Juan do conhecimento', bem como com o último aforismo do livro, aquele mesmo que é finalizado com a pergunta 'oder?'. Don Juan do conhecimento é uma máscara para o próprio Nietzsche ${ }^{16}$ e, enquanto tal, o momento do texto em que Nietzsche encena a si mesmo através de uma máscara: a máscara como Don Juan do conhecimento! ${ }^{17}$

Chamo atenção nesse ponto para o que denomino de heurística do distanciamento: a estratégia crítica da práxis autogenealógica em Aurora. A meu ver, o ponto de culminância dessa estratégia é precisamente quando Nietzsche utiliza Don Juan do conhecimento como figura de pensamento: Don Juan não ama "as coisas que conhece", mas tem "espírito, volúpia e prazer na caça e nas intrigas do conhecimento [...] - até que enfim nada mais lhe resta a caçar, senão o que é absolutamente doloroso no conhecimento." (A 327) A ênfase no processo 'doloroso' de busca, e não na finalidade da busca é o ponto de vinculação com a heurística do distanciamento, na medida e quem ela também consiste em ininterrupto questionamento. Não

16 Cf. W. Ries; K-F. Kiesow, "Von Menschliches, allzumenschliches bis zur Fröhlichen Wissenschaft", in Henning Ottmann (Hrsg.), Nietzsche: Leben-Werk-Wirkung. StuttgartWeimar: J.B. Metzler Verlag, 2000, p. 109.

17 Para uma análise das interlocuções de Nietzsche nesse aforismo, vale dizer, com o Simpósio de Platão, com o 'divertissement' de Pascal, com a ópera Don Giovanni de Mozart, e com o romance De l'amour de Stendhal, cf. a precisa e interessantíssima análise de Marco Brusotti, Die Leidenschaft der Erkenntnis, p. 295ss. 
se trata de interrogar para encontrar alguma resposta, mas intensificar o próprio questionamento, mesmo sabendo que essa práxis interrogativa é o mais 'doloroso'. O livro que termina com uma pergunta só poderia mesmo ter Don Juan como figura de pensamento, aquele cuja distinção é a práxis do procedimento, assim como a constante práxis interrogativa nietzscheana.

Dois aspectos no aforismo, porém, podem ser levados em conta nessa reflexão. Por um lado, a máscara empregada por Nietzsche como Don Juan se revela pela sua própria reivindicação de ter sido o primeiro a descobri-lo no conhecimento: "O Don Juan do conhecimento: nenhum filósofo e nenhum escritor o descobriu ainda." Essa reivindicação de paternidade já indica como Nietzsche entende genealogicamente a si mesmo por meio de uma miríade de interlocutores. 'Filósofos' e 'escritores' que ainda não descobriram essa figura servem, por conseguinte, como lente por meio da qual o próprio Nietzsche enxerga a si mesmo, distanciando-se deles para reivindicar ser o seu descobridor. Dessa forma, é importante enfatizar que Don Juan não é uma identificação autobiográfica de Nietzsche, mas apenas uma figura que serve para Nietzsche exprimir seus próprios pensamentos. Nietzsche não escreve no aforismo que é Don Juan, uma vez que reivindica sua mera paternidade, exercendo a função de lente de aumento por meio da qual se compreende melhor a estratégia nietzscheana de distanciamento e autogenealogia. Por meio de Don Juan, Nietzsche está interessado no que é 'doloroso' no conhecimento e, por isso mesmo, ele tem sempre que 'naufragar', conforme escreve no último aforismo do livro.

Por outro lado, ao 'Don Juan do conhecimento' - que já não ama as 'coisas que conhece' - resta apenas caçar o "Wehethuende" (o que é doloroso) no conhecimento, vale dizer, a impetuosidade mesma pela própria caça, a avidez pelo próprio distanciamento e pelo ininterrupto questionamento. A sedução pelo "Wehethuende" no conhecimento se converte então em argumento autorreferencial, a contínua busca dolorosa e infeliz sem qualquer pretensão de finalidade, mas reduzindo-se à própria busca. O último aforismo de Aurora exprime igualmente essa autorreferencialidade argumentativa, quando Nietzsche faz uma série de perguntas direcionadas ao livro inteiro, a si mesmo e a seus leitores. No final do livro, o 'Wehethuende' que seduz Nietzsche é encontrado em uma das perguntas colocadas por ele, ao se referir precisamente à 'avidez' da busca, ou seja, ao 'Wehethuende', como aquilo que tem mais alto valor: "Para onde nos arrasta essa poderosa avidez, que para nós vale mais que qualquer outro desejo?" (A 575) Nesse caso, se as perguntas de Nietzsche no aforismo final são sobre navegar, por meio de 'Don Juan do conhecimento' ele também não pode se apaixonar por algo que encontre em outros mundos, mas apoiar-se unicamente no 'Wehethuende' da própria 
navegação. Obviamente sua resposta a isso não poderia ser outra a não ser uma nova pergunta, aludindo, dessa vez, não ao amor por algo que possa ser encontrado, mas ao seu naufrágio no infinito, isto é, uma contínua necessidade de distanciamento: "Dirão as pessoas, algum dia, que também nós, rumando para o Ocidente, esperávamos alcançar as Índias - mas que nosso destino era naufragar no infinito?" (A 575)

Contextualmente, o último aforismo 575 e o aforismo 327 sobre Don Juan do conhecimento estão ligados precisamente com o aforismo no qual Nietzsche anuncia sua "nova paixão": a "paixão do conhecimento" (A 429). $\mathrm{O}$ "Wehethuende" da busca no 327, bem como a 'avidez' de distanciamento no 575 são precisamente o que no aforismo 429 é caracterizado sob o signo de "amantes infelizes":

Mas nosso impulso ao conhecimento é demasiado forte para que ainda possamos estimar a felicidade sem conhecimento ou a felicidade de uma forte e firme ilusão; apenas imaginar esses estados é doloroso para nós! A inquietude de descobrir [...] tornou-se tão atraente e imprescindível para nós como o amor infeliz para aquele que ama [...] -; sim, talvez nós também sejamos amantes infelizes! O conhecimento, em nós, transformou-se em paixão que não vacila ante nenhum sacrifício e nada teme, no fundo, senão a sua própria extinção; (A 429. O grifo é meu)

Temível ao amante infeliz não é tanto perder ou se apaixonar por algo, mas justamente não mais amar; a práxis interrogativa de Nietzsche, assim me parece, exprime da mesma maneira aquela paixão do 'amante infeliz', especialmente quando direciona essa paixão contra si próprio: 'talvez nós também sejamos amantes infelizes!', em mais uma tentativa de compreender melhor a si mesmo, ao se reencontrar no processo criticado por ele.

No 'Prólogo' tardio de Aurora, mas também no próprio livro de 1881, Nietzsche menciona expressamente seu anseio por "caminhos próprios" (A, Prólogo 2). ${ }^{18}$ O livro revela uma engenhosa estratégia de distanciamento que iria se desdobrar até seus últimos escritos. Ora, é certo que Nietzsche não fala especificamente de si mesmo em Aurora - tal como o faz em sua autogenealogia Ecce homo -, porém, certamente se intensifica em Aurora sua busca por 'caminhos próprios', seu lugar como o filósofo

\footnotetext{
18 Contextualmente, o aforismo 2 do 'Prólogo' tardio tem de ser lido ao lado do aforismo 484 intitulado precisamente "O caminho próprio": "Se damos o passo decisivo e tomamos o caminho denominado 'próprio', subitamente revela-se para nós um segredo: todos, também os que nos eram próximos e amigos, imaginavam-se até então superiores a nós e ficam ofendidos. [...] Que fazer então? Meu conselho é: inaugurar sua soberania, garantindo antecipadamente a todos os nossos conhecidos um ano de anistia por pecados de toda espécie."
} 
Nietzsche. Tanto a heurística de distanciamento e sua práxis interrogativa, quanto a figura de 'Don Juan do conhecimento', são as variáveis com as quais Nietzsche constrói aos poucos as condições para uma de suas primeiras tentativas de entender a si mesmo, e a si mesmo como filósofo, genealogicamente.

\section{Referências}

Brusotti, M. Die Leidenschaft der Erkenntnis: Philosophie und ästhetische Lebensgestaltung bei Nietzsche von Morgenröthe bis Also Sprach Zarathustra. (Monographien und Texte zur Nietzsche-Forschung). Berlin/ New York: Walter de Gruyter, 1997.

Epicteto, Entretiens. Trad. Joseph Souilhé. 1943-1965. 4v. (Col. Belles Lettres), 2007.

Kaulbach, F. Nietzsches Idee einer Experimentalphilosophie. Köln/Wien: Böhlau, 1980.

MurraY, Peter D. Nietzsche's Affirmative Morality: a revaluation based in the Dionysian World-View. Berlin/New York, 1999.

Nietzsche, F. Sämtliche Werke. Kritische Studienausgabe in 15 Bänden. (KSA) Hrsg. Giorgio Colli und Mazzino Montinari. Berlin/New York: DTV \& Walter de Gruyter, 1999.

, Sämtliche Briefe. Kritische Studienausgabe. (KSB) Hrsg. Giorgio Colli und Mazzino Montinari. Berlin/New York: DTV \& Walter de Gruyter, 1986. , Humano, demasiado humano. (Trad. Paulo César de Souza). São Paulo: Companhia das Letras, 2000.

, Aurora. (Trad. Paulo César de Souza). São Paulo: Companhia das Letras, 2004.

, A Gaia Ciência. (Trad. Paulo César de Souza). São Paulo: Companhia das Letras, 2001.

, Além do bem e do mal. (Trad. Paulo César de Souza). São Paulo: Companhia das Letras, 1998.

, Genealogia da moral. (Trad. Paulo César de Souza). São Paulo: Companhia das Letras, 1998.

, O Caso Wagner/Nietzsche contra Wagner. (Trad. Paulo César de Souza). São Paulo: Companhia das Letras, 1999.

, Crepúsculo dos ídolos. (Trad. Paulo César de Souza). São Paulo: Companhia das Letras, 2006.

, Ecce homo. Como alguém se torna o que é. (Trad. Paulo César de Souza).

São Paulo: Companhia das Letras, 2004.

RIES, W.; KIESOW, K-F. Von Menschliches, allzumenschliches bis zur Fröhlichen

Wissenschaft. In: Ottmann, H. (Hrsg.) Nietzsche: Leben-Werk-Wirkung. Stuttgart-Weimar: J.B. Metzler Verlag, 2000. 
Schopenhauer, A. Aforismos para sabedoria de vida. Trad. Jair Barboza. São Paulo: Martins Fontes, 2006.

Stegmaier, W. Philosophie der Fluktuanz: Dilthey und Nietzsche. Göttingen: Vandenhoeck \& Ruprecht, 1992a.

, Nietzsches Kritik der Vernunft seines Lebens: Zur Deutung von Der Antichrist und Ecce homo. In: Nietzsche-Studien, n. 21(1992b), p. 163-183.

TARquínio, Antônio C. Epicteto e a paixão no coração do pensamento. As duas cusas de Crisipo e o mergulho em Deus. In: Cadernos UFS-Filosofia, vol. 5 (2009), p. 35-48.

Tongeren, Paul v.,"Vom 'Arzt der Kultur' zum 'Arzt und Kranken in einer Person'“. In: Adreas Urs Sommer (Hrsg.), Nietzsche, Philosoph der Kultur(en)?. Berlin/New York: Walter de Gruyter, 2008. p. 11-29.

, O filósofo como clínico da crítica à cultura. In: Estudos Nietzsche (trad. Jorge L. Viesenteiner), v. 1, n. 2 (2010), p. 265-286.

WotuIng, P. Nietzsche et le problème de la civilisation. Paris: PUF, 1995. 


\title{
RESUMO
}

Esse artigo objetiva analisar uma das primeiras tentativas bem sucedidas de Nietzsche de compreender genealogicamente a si mesmo e a si mesmo como filósofo, a partir do livro Aurora de 1881, por meio das noções de distanciamento e questionamento. A estratégia de distanciamento, compreendida como diferenciação da diferenciação, consiste em colocar a 'questão do por quê?, do para quê?', dirigida à 'confiança na moral', aos seus leitores e, indiretamente, ao todo do próprio questionamento de Nietzsche. Assim, o distanciamento crítico é, simultaneamente, a tentativa de compreensão genealógica de si mesmo. Essa empresa crítica é conduzida pela estratégia argumentativa de distanciamento dos 'erros da razão', na medida em que essa confrontação exerce o papel de lente de aumento para o próprio Nietzsche que, em Aurora, é compreendida na análise do aforismo intitulado "A ilusão da ordem moral do mundo". Uma figura de pensamento para essa autogenealogia foi referida por Nietzsche como Don Juan do conhecimento, que igualmente cumpre a função de lente de aumento para Nietzsche.

Palavras-chave: autogenealogia - distanciamento - questionamento - ordem moral - Don Juan

\begin{abstract}
This paper aims to analyze one of Nietzsche's first successful attempts to genealogically understand himself and himself as a philosopher, in the book Morgenröthe published in 1881, based on the notions of distancing and questioning. The strategy of distancing, understood as differentiation of differentiation, consists of placing the 'question of why?, what for?', directed to the 'confidence in the moral', to the readers as well as, indirectly, to the whole of Nietzsche's own questioning. Thus, the critical distancing is, simultaneously, the attempt of a genealogical understanding of himself. This critical procedure is conducted by the argumentative strategy of distancing from the 'errors of reason', inasmuch this confrontation plays the role of a magnifier to Nietzsche himself, whose confront in Morgenröthe can be understood through the aphorism 563, entitled "The illusion of the moral order of the world". A figure of thought to this important genealogy was referred by Nietzsche as Don Juan of knowledge, which performs the function of a magnifier for Nietzsche as well.
\end{abstract}

Keywords: selfgenealogy - distancing - questioning - moral order - Don Juan 